\title{
Light and Electron Microscopy on the Proximal Convoluted Tubules During the Postnatal Development*
}

\author{
By \\ Fujio Yoshimura and Mikio Nakamura \\ Department of Histology and Embryology, Jikei-Kai School \\ of Medicine, Shiba, Minatoku, Tokyo
}

It has been established in the mammalian kidneys during the postnatal development that the primordial tubules, blastema, are piled up beneath the renal capsula, elongating themselves in order to be conjugated with the tips of the collecting tubules which had been already accomplished in embryonic life (Kittels on 1917; A rataki 1926 ; B axter and $Y$ of $f$ e y 1948). The proximal convoluted tubules in embryonic and infantile growing kidneys are provided with the simple and uncluttered ultrastructure, which is considered useful to understand the complicated ultrastructure in the adult. There have been so far a few reports about this subject. C la rk (1957) described the differentiation of tubular cells in newborn mice by electron microscope.

$\mathrm{S} \mathrm{u} \mathrm{z} \mathrm{u} \mathrm{k} \mathrm{i} \mathrm{(1958)} \mathrm{carried} \mathrm{out} \mathrm{the} \mathrm{electron} \mathrm{microscopy} \mathrm{on} \mathrm{the} \mathrm{dif-}$ ferentiation of the cells of proximal convoluted tubule in embryonic, newborn and adult rats. Le es o n $(1959,1960)$ made the electron microscopy on the development of mesonephros and metanephros in rabbits. On the other hand, investigatons on the ultrastructure concerning the the proximal convoluted tubules of the adult mammals have been accumulated ( $\mathrm{Sjöstrand}$ and $\mathrm{Rhod}$ in 1953 ; $\mathrm{Pol}$ ic a rd, 1954; R hodin 1954, 1958a, b; Peas e 1955; W e is s 1955; Rollhäuser and Vogell 1957; Rollhäuser 1957; Elias 1957; Montgomery and Breeman 1958; Miller 1960; $\mathrm{Schmidt}$ 1960). Above all, the diagrammatic representation by $\mathrm{R}$ hod in $(1958 \mathrm{a}, \mathrm{b})$ has been highly appreciated. But it seems dif-

* Reported in participation with the symposia on "Histology and Cytology of the Kidney" at the 69th annual meeting of the Japanese Association of Anatomists in Niigata City, May 3, 1964. 
ficult in some respects to explain exactly both mechanisms, secretion and reabsorption. The ultrastructure of the proximal convoluted tubules in the adult is so puzzling that the following subjects remain unsolved: (1) the appearance of microvilli and luminal formation, (2) the development of tubular invagination, (3) the structure of vacuoles appearing beneath the brush border and their derivation, (4) the big granules, their origination and an interrelation to the vacuoles, (5) a connection between vacuoles and underlying slender endoplasmic reticulums, (6) the basal compartments and their significance, (7) the foot processes at the basal part of cell-body, (8) the contour of a single cell. In answering the above questions, the proximal convoluted tubules were investigated electron microscopically with the materials of newborn and growing rats. These rats give the precise, simplified ultrastructure. The authors were able to modify the diagram by $\mathrm{R}$ h o d in from some results obtained and to discuss concerning the functional significance of the ultrastructure.

\section{Materials and Methods}

Wistar-Imamichi strain male rats were used in this investigation. They, in litter mate breeding from the same parents in our laboratory, were fed with the pellet diets. The date of sacrifice of animals was designed as follows: the moment of delivery, 1st, 2nd $3 \mathrm{rd}$, 4th, 5th, 6th, 7th, 9th, 12th, 15th, 21st, 30th, 40th, 50th, 60th and 90 th postnatal day in the sequence. All day-groups consisted of 5 or 6 rats. After decapitation, the bilateral kidneys were removed from the animals for the measurement of weight and size. For the light microscopic observation, kidney tissues were fixed with $10 \%$ acrolein solution for 24 hours and put in Stieve's fixative for 2 days; paraffine sections $4 \mu$ in thickness, partial serial sections, were stained with periodic acid Schiff's reagent (PAS) with the counterstain of iron-hematoxylin (M. Heide $n$ ha i n).

For the electron microscopy, small tissues of the kidney were fixed with $2 \%$ osmium tetroxyde-s-collidin mixture $(1: 1) \mathrm{kept}$ in $\mathrm{pH}$ 7.5 for the period of 2-3 hours. Following the fixation, the tissues were dehydrated in increasing percentage of cold ethanol, and treated. with propylenoxyde for 10 minutes, then infiltrated and embedded with Luft's epon resin. The sections were cut with Porter-Blum ultratome and mounted on coupper grids. The staining of sections was tried with the routine procedure recommended by 
Millonig (1961) and Reynalds (1963). The sections were observed with Akashi Tronscope $60 \mathrm{~B}$ electron microscope.

\section{Observations}

\section{Body-weight, kidney-weight and kidney-length}

The average body-weight curve in each day-group was shown in Fig. 1, revealing the easy ascending gradient. The kidney-weight

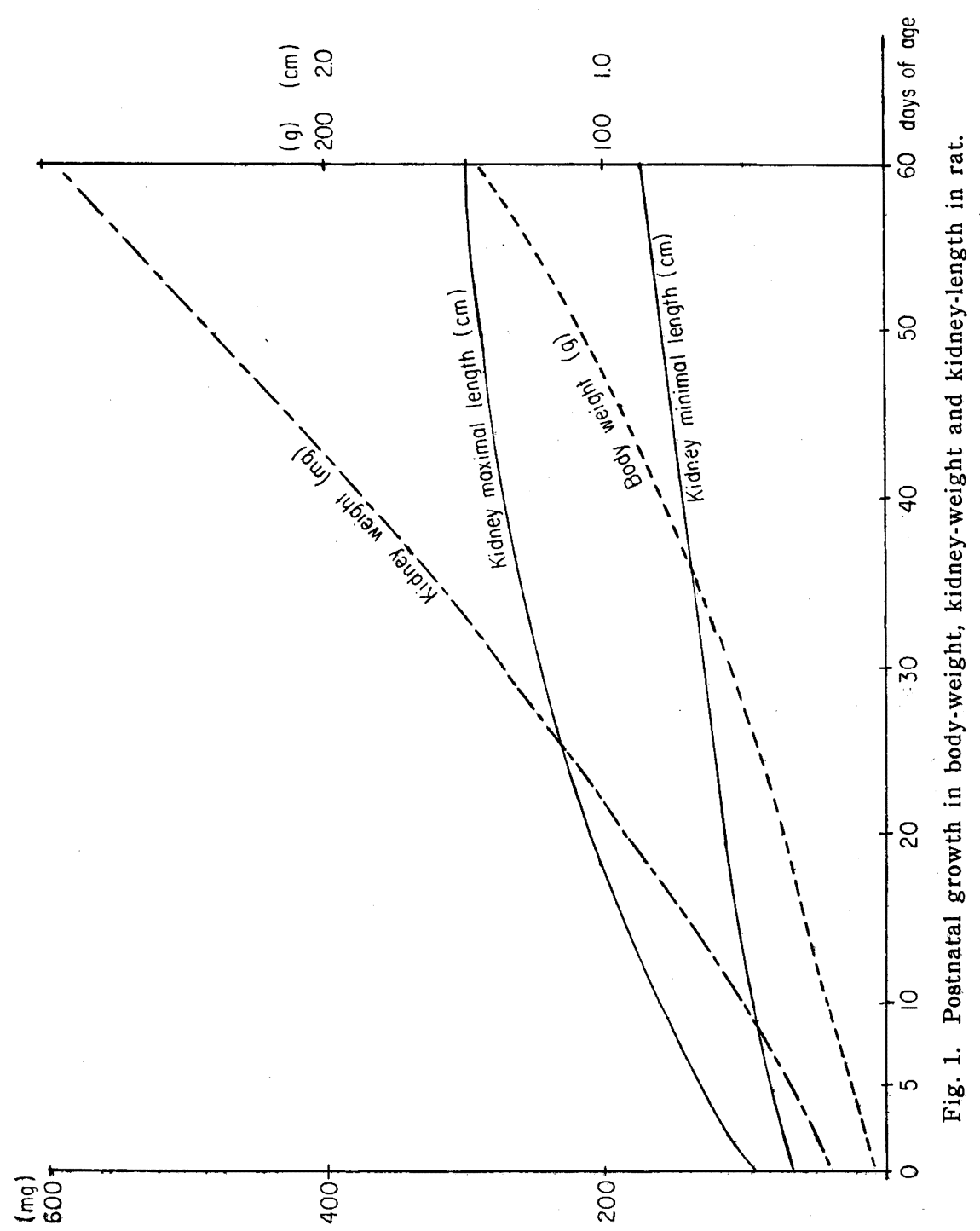


(mean value of bilateral kidneys) increased promptly, amounting in 60 days to over 10 times of that at birth. Maximal and minimal length of kidneys increased more as the animals grew older, but in 60 days it did not yet reach to two times of that at birth. That the growing rate of kidney-size was behind that of the weight might be because the interior tissue of kidney was substituted by a number of parenchymal cells which penetrate through the connective tissue.

\section{Histological findings in renal tubules during the postnatal development}

At birth, the kidneys contain many intertubular connective tissue. The glomeruli and the implicated nephrons, which had already differentiated in some extent at the innermost area of cortex at the period of embryonic mesonephros, develop further into the late nephron after birth (Fig. 2). In those glomeruli, large in size, several capillary loops are included, and the glomerular epithelium is situated on their basement membrane. After birth, the early nephron in newborn rats prolong themselves slightly into the superficial area of cortex without the heavy bending. In the middle area of cortex, the transsections of proximal and distal convoluted tubules are of low frequency, while numerous sections of fully differentiated late nephrons are found at the innermost area on account of extensive elongation of nephron (Fig. 2). The free surface of dark epithelial cells of these late proximal convoluted tubules has been already equipped with the brush border stained with PAS. Loop of $\mathrm{Henle}$ of the nephron descends into medulla and reflects upwards, but it has not been assigned to the early nephron.

Detailed histological examination on the outer neogenic zone of cortex have shown that the cells of blastema surrounded by the basement membrane may be resulted from the aggregation of mesenchymal cells scattered beneath the capsula. Blastema turns into the primordial tubule which begins to include a lumen but sometimes devoid of it. The central portion of them tends to be clear and exclusive of nuclei, suggesting a beginning of luminal formation (Figs. 2 and 3). It has been generally accepted that they have potential affinity to fix on the tip of the initial collecting tubules. The neogenic cells in blastema posses the strong proliferating ability, as mitosis is frequently in it. In order to prolong the length of nephrons, proliferation mainly owing to mitosis remains 


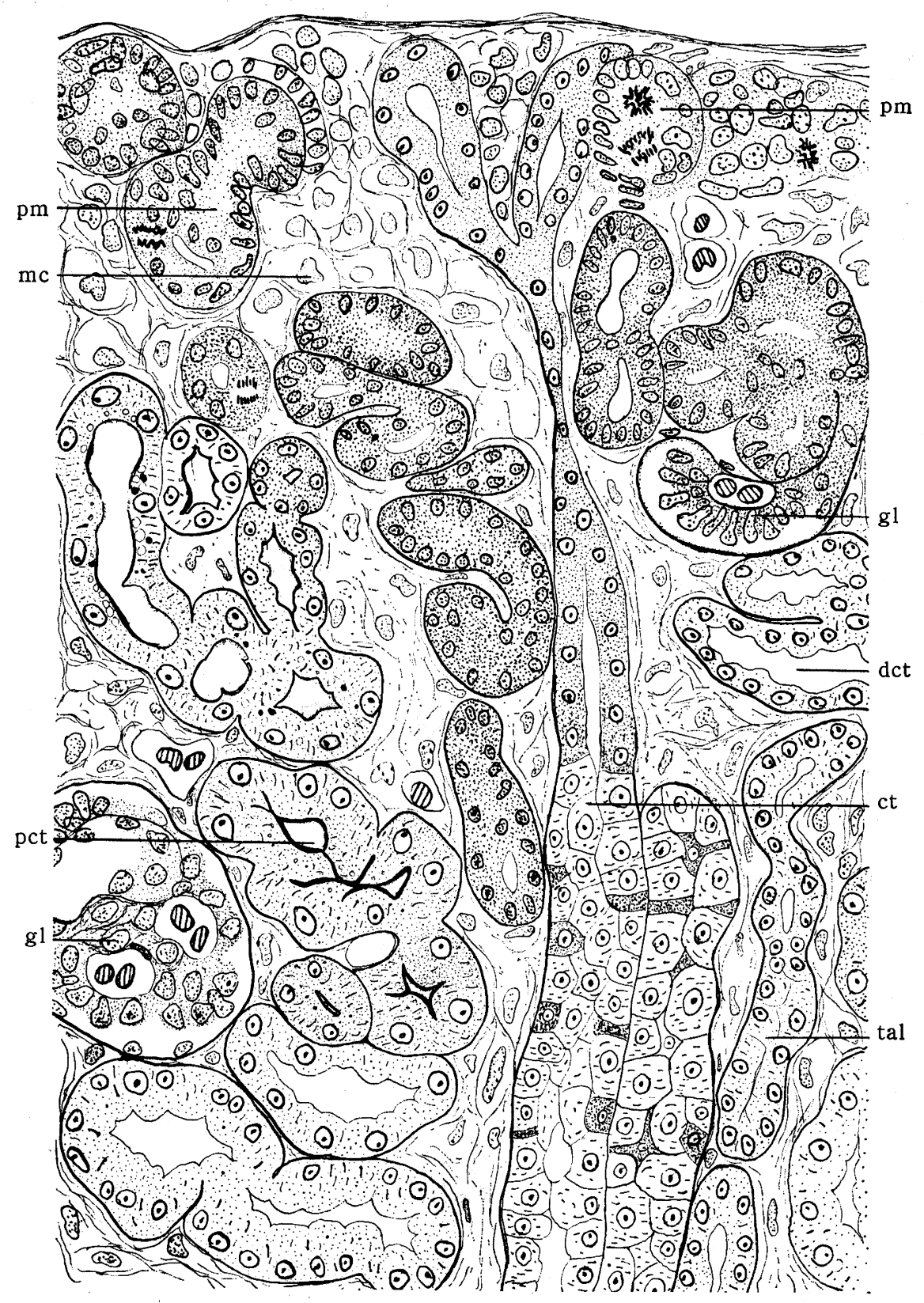

Fig. 2. The outer neogenic zone of renal cortex in rat at birth. pm, primordial tubule; mc, mesenchymal cell; gl, glomerulus; pct, proximal convoluted tubule; dct, distal convoluted tubule; tal, thick ascending $\operatorname{limb}$; ct, collecting tubule. 
in an advancing state even after the combination with the collecting tubules (Figs. 2 and 3).

In the next stage in differentiation of nephron, after the tip changes into glomerulus, a nephron begins to bend or crook singlly downwards at the middle area of cortex. This part sectioned indicates usually a dark shadowy epithelium with elongated nuclei; its free surface is not yet covered with thick brush border (Fig. 2). The development of nephron is quite diverse in degree with the depth of cortex. In fact, the histological picture of proximal convoluted tubules varies in corresponding to their localization even

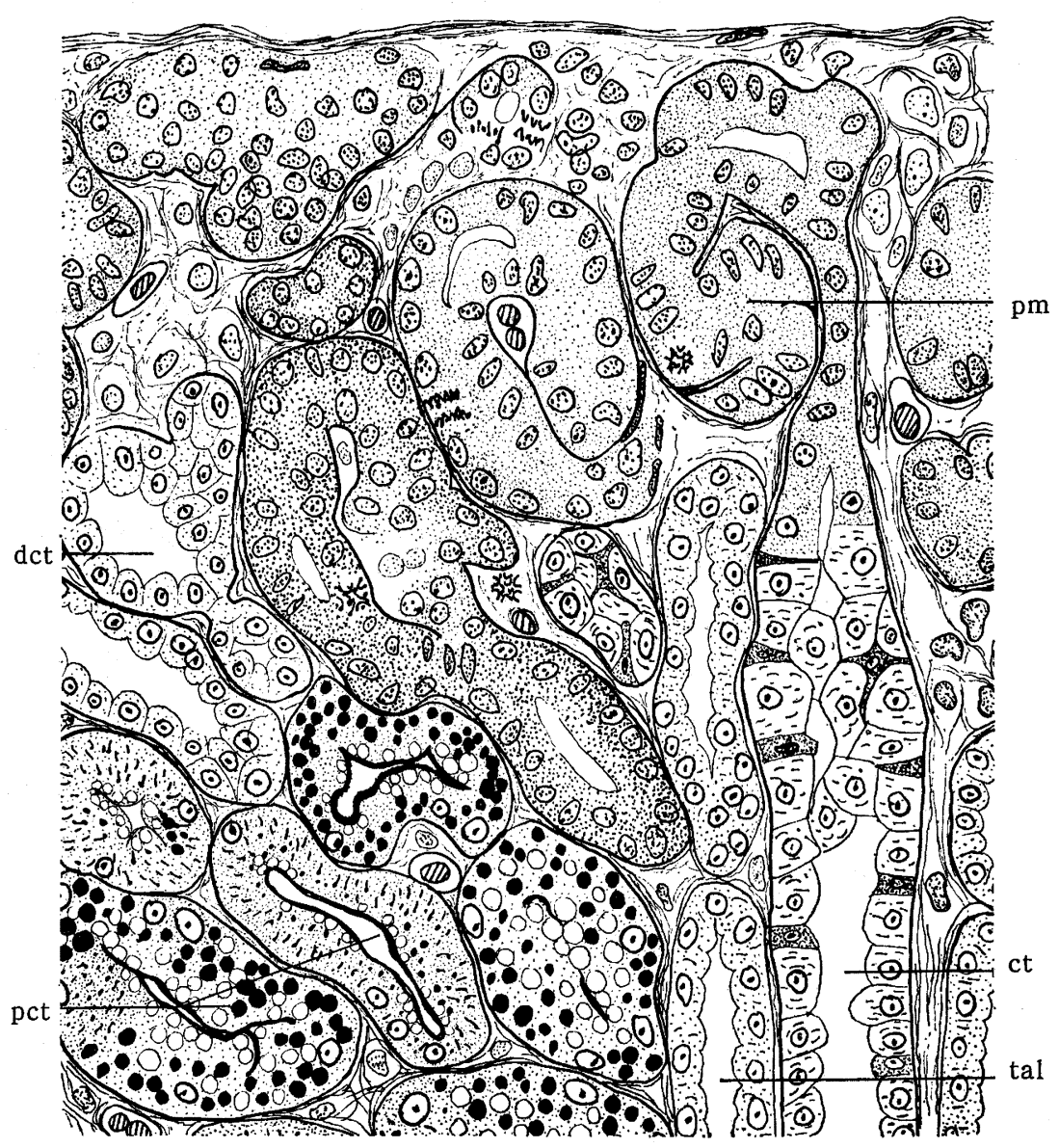

Fig. 3. The outer neogenic zone of cortex in rat, the first postnatal day. The late nephrons are located at the deeper area but the early ones at the upper part. The cells of the proximal convoluted tubule in the late nephron are packed with the coarse granules and vacuoles. The intertubular connective tissues are abundant yet. 
among the animals born on the same day (Figs. 2 and 3).

In the first postnatal day, the latest nephrons at the innermost area furnish the maturated proximal convoluted tubules composed of one layer of truncated pyramidal epitehial cells, showing the indistinct boundary between cells (Fig. 3). Their cytoplasm is packed with the coarse granules combinedly stained with iron-hematoxylin and PAS, associated with the vacuoles with the same size which may be derived from the granules by liquefying. The vacuoles are inclined to be concentrated at the apical part. Loop of $\mathrm{Henle}$ consists of the columnar lining cells, but it does not develop enough to distinguish both thick ascending and thin descending limbs. The sections of loop of $\mathrm{Henle}$ in medulla are reduced in diameter. After ascending, nephrons bend again, representing a distal convolution, and the cells are dark and provided with the distinct cell boundary. Because of the continuous neoformation, nephrons with the various differenciations are mingled at the superficial or middle area of cortex. Thus, nephrons develop in the postnatal life in the same way as in embryo.

In the second postnatal day the peculiar package of coarse granules is observed in cells of the proximal convoluted tubules of the underlying latest nephrons, but the granules disappear after the third day. The cells contain numerous rodlike mitochondria, arranging each other perpendicularly in parallel at the basal part of cell-body without the temporary storage of granules. The parallel distribution of mitochondria manifests the basal striation formation. Many sections of proximal convoluted tubules prove the achievement of manifold bendings of nephrons. The intertubular connective tissues become less in quantity, as the newly formed nephrons increase in number. In the 4 th day, the entire cortex is rich in sections of nephrons, and the basal striation is typical as much as that segment of nephron in the adult. All glomeruli at the various depths contain usually the tortuous capillary loops, and subsequently the implicated nephrons present an evidence of progression in the development. It is a characteristic after the 4th day that the numerous vacuoles are distributed transversally in row under the brush border. The neoformation of blastema is ceased in the 9th day (Fig. 4), and the prolongation of nephron becomes a main modification in the development of the late nephrons; it would be participated in forming the medullary radiation that the thick ascending limbs run radially in parallel each other. It is noted that some cross-sections of the late nephrons adhere to the capsula. 


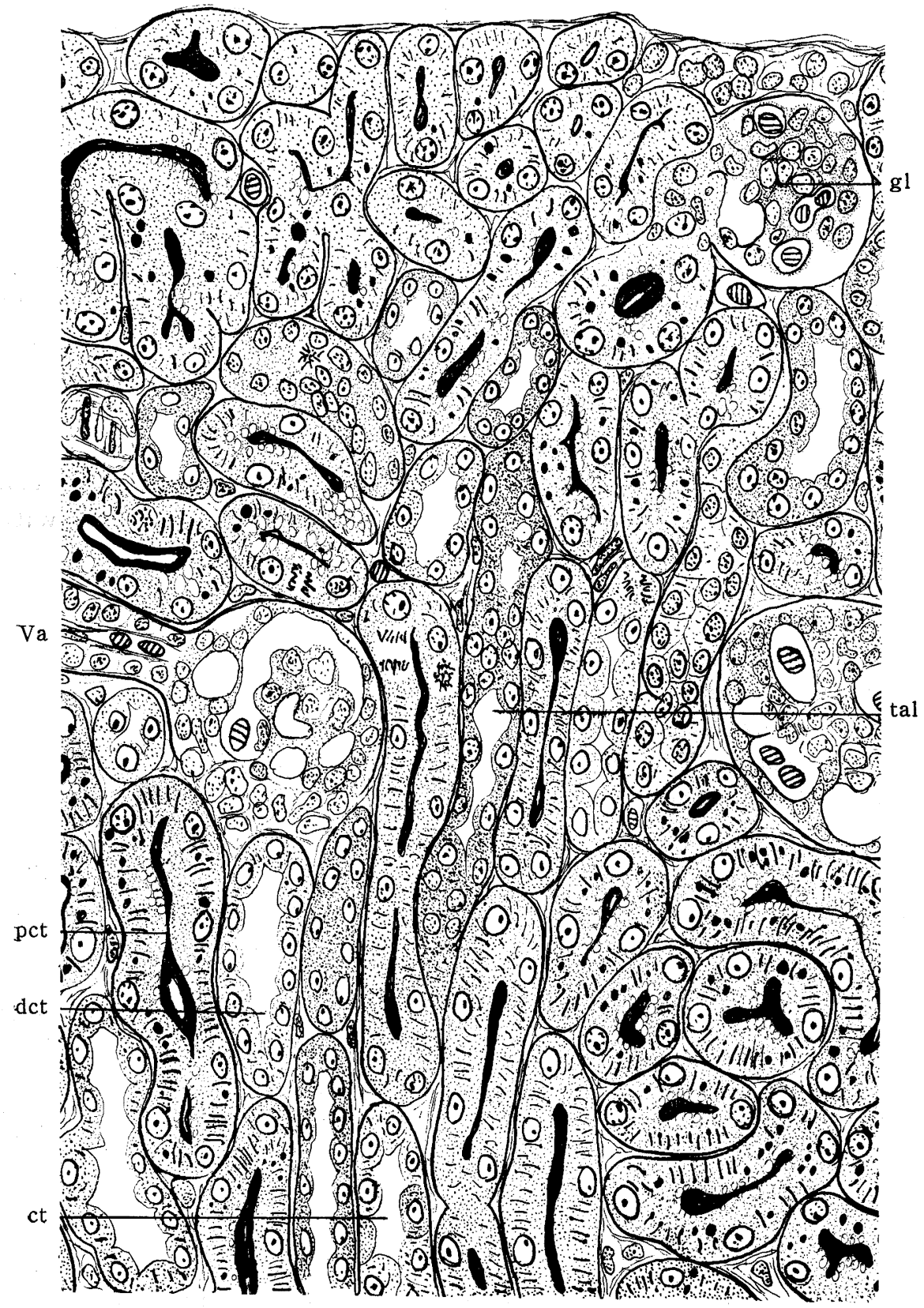

Fig. 4. Renal cortex, rat, the 9th day. The neoformation of nephron is ceased and the differentiated renal tubules are adherent to the capsula. The intertubular connective tissues decrease in amount. The cells of proximal convoluted tubules contain vacuoles and coarse granules, and the basal striation becomes typical. Va, Vas afferens. 
and result in the exclusion of neogenic zone of outer cortex. From the 9 th to 12 th day the development of kidneys is almost coordinative, but vacuoles beneath the brush border tend to diminish in number (Fig. 4). In addition, the coarse granules yield sparsely at the basal part. From the 20th to 60th day, histological feature of nephrons is compatible with that in the adult. But mitosis is observed in the cells of proximal convoluted tubules, and prolongation still proceeds progressively in the nephron. In general, the additional neoformation of nephrons is succesive to the 9th day with an aim of augmentation in kidney volume, and after the 9 th day only prolongation of nephron is performed owing to the mitosis in order to increase the kidney-weight.

\section{Electron Microscopy}

\section{1) Outgrowth of microvilli and luminal formation in} proximal convoluted tubules

In light microscopy, as mentioned above, the lumen is virtually absent in blastema but present in the late proximal convoluted tubule. In the electron microscopy, it has been ellucidated that the primordial tubules have lumen apparently. The luminal formation is, therefore, almost synchronized by the induction of blastema. Its primitive cells are simple columnar; as the nucleus is located excentrically at the basal part, the superficial portion of the cytoplasm in which mitochondria are excluded is immense (Fig. 8). This is a reason why the center of primordial tubules looked pale and amorphous on light microscopy. The cytoplasm of primitive cells is monotoneous, though the amount of microsomes and slender rough endoplasmic reticulums is moderate.

The double plasmamembranes bend sharply in some places between cells in the central area of primordial tubule (Fig. 8). The finger-like narrow cytoplasm bordered by its inner membrane is high in electron density. The profuse occurrence of these flexions of the membrane is followed by the alienation of inner and outer membranes, interposing the space between them (Fig. 9). This picture exactly means a beginning of the luminal formation. The inner narrow cytoplasm is identical with the tiny processes denominated microvilli. The external vaginae, into which the inner processes were inserted, represents a profound cleft. In an event that the interspace is enough expanded, the cytoplasmic processes veiling the surface of the opposite cells have the appearance of brush border 
(Fig. 10). The flexions of double membranes (Fig. 11) could frame the first step of the outgrowth of microvilli. Thereafter the bending is repeated in the another parts and eventually forms several narrow lumens among cells. Observations on the primordial tubules showed that the lumen was never aggregated into a single dilated one and that the plasmamembrane did not bend till the blastema

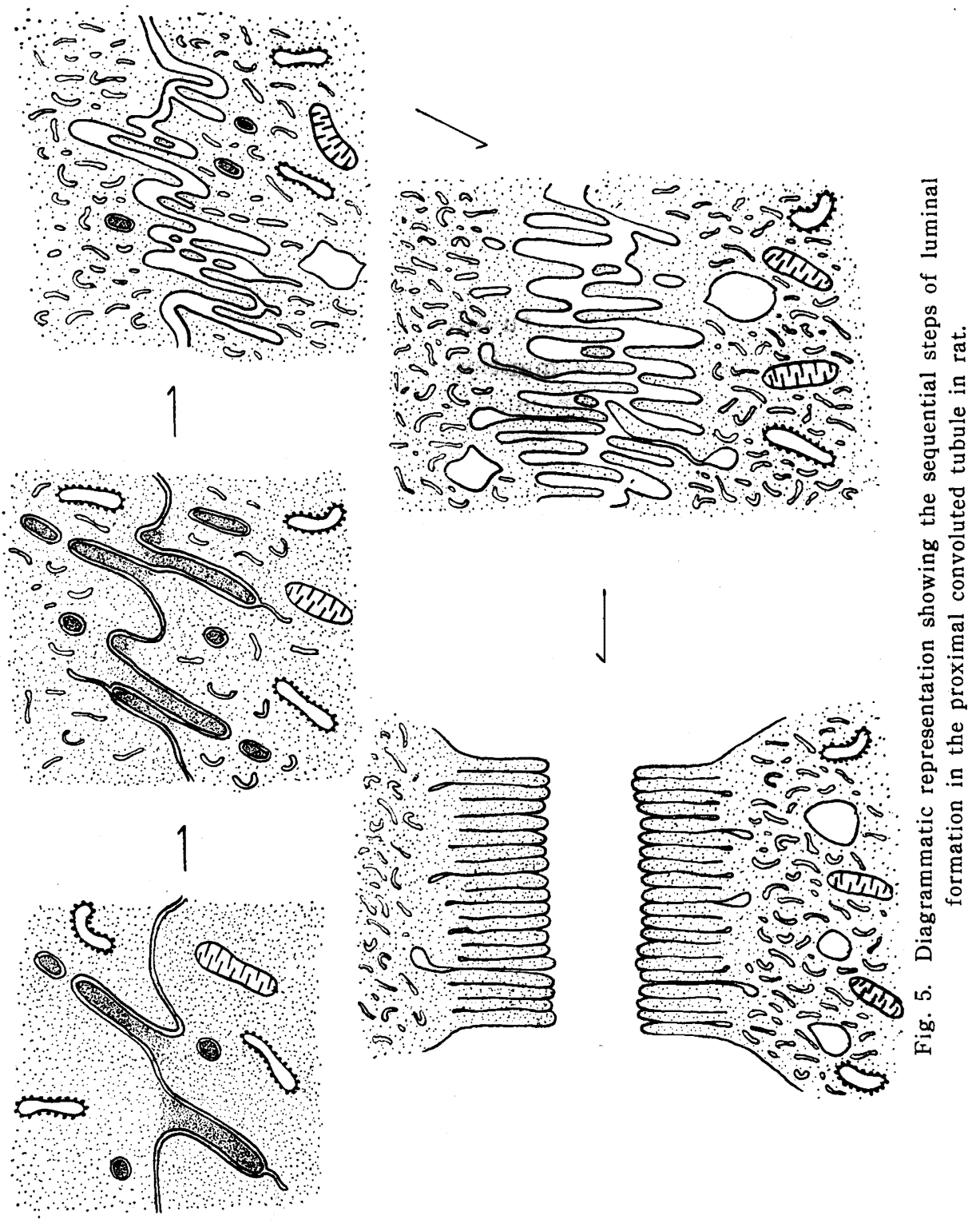


remained indifferentiated. Thus the dense arragement of reflexions of plasmamembrane is considered a premonitor of the interdigitation. Suzuki (1958) considered that the brush border was formed by the gradual differentiation of cytoplasmic small processes on the free surface facing the lumen, but the present observation is contrary to his view. From birth to the 9 th day, there is a specializing part of cytoplasm which deprives the microvilli on its free surface in the late proximal convoluted tubules. It bulges in the lumen to be in contact with the microvilli of the opposite surface. This part of the cell without the microvilli is constantly pale because organellae are few (Fig. 12); the specialization continues until the end of the development (up to the 30th day). The prolongation of microvilli and augmentation in their population density results naturally in the closure of lumen. In fact, most of lumen in proximal convoluted tubules are closed in developing and in the maturated nephron. The present observation in the adult $(60,90 \mathrm{th}$ day) enabled us to conceive that the shape and size of lumen might be conditioned on the functional state of nephron, especially on the timing of transporting rythmus designated to the lumen. Diagrammatic representation showing the development of lumen was illustrated in Fig. 5.

\section{2) Development of tubular invagination}

The minimum interspace between microvilli has invaginated deeply down during the eariest primordial period. This split is quite identical with the tubular invagination. It would be a kind of channel, either large $(20-30 \mathrm{~m} \mu)$ or small $(5-10 \mathrm{~m} \mu)$ in diameter, which runs perpendicularly or obliquely (Fig. 9). This channel with high electron density, surrounded by the smooth limiting membrane, is utterly different from the smooth endoplasmic reticulum, since it is not round but flat in cross-sections. It represents tubulo-saccular branchlets. It is emphasized that the channel has already appeared in the late nephron in newborn rat. From birth to the 9th day, the tubular invagination increased gradually in population and in length. It is also understood in the present observation that the layer packed with tubular invaginations grows in width in proportion to the differentiation of microvilli (Fig. 6). However, their shape and internal structure are not necessarily modified with the developmental process. The tubular invagination ends into a huge blind sack or vacuole (Fig. 13). It is not always but occasionally 


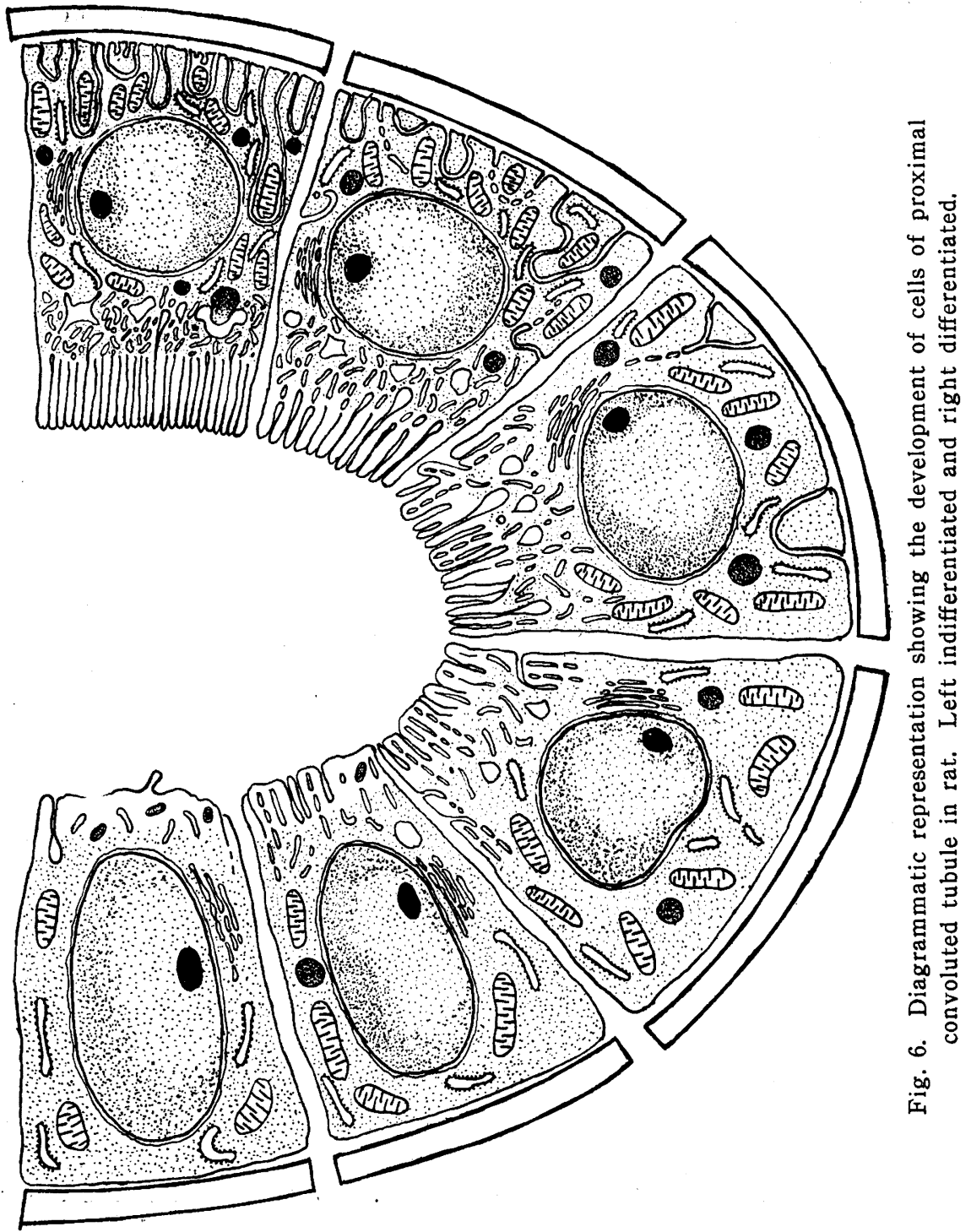

checked in all invaginations. The vacuoles tend to increase in number with the development of nephrons. Hence the origination of vacuoles has been precisely ellucidated from the above findings. Its schematic representation was shown in Fig. 5. 


\section{3) The structure of vacuoles appearing beneath the microvilli}

It has been well known in the light microscopic observation that there exist many vacuoles beneath the brush border. Since the 6th day, the vacuoles increased abruptly in number and were distributed transversally in a row. The electron microscopic picture of the vacuoles was illustrated in Fig. 13. They are not round but flat sacks with irregular shape; two or three tubular invaginations terminate in a vacuole. There is an evidence enough to demonstrate the continuity of the invagination to the vacuoles (Fig. 17). This kind of vacuole arises infrequently in the proximal convoluted tubule cells of the early nephron before the 4th day, but with a development of this segment, the vacuoles have been elevated in frequency. In a cell of accomplished proximal convoluted tubule, several vacuoles are usually present and the peak is in 6 to 12th day. The vacuoles tended to decrease in number thereafter.

\section{4) Big granules and their origination}

D a vies (1954) already reported in light microscopy that there occur numerous big granules in cells of proximal convoluted tubule in a variety of mammalian foetus. The conspicuous concentration of the big granules is a specific change in second and third postnatal day, and it is responsible for the transient proteinuria after birth. $\mathrm{D}$ a vies regarded them as the reabsorbed protein granules. In our observation, enormous granules reaching to approximately $500 \mathrm{~m} \mu$ in diameter are ramdomly accumulated in the cytoplasm (Fig. 14). These granules surrounded by the distinct limiting membrane contain the substances variable in density from high to low, and are apt to be low at the apical part but conversely high at the basal part. Sometimes they are full of homogeneous material in which dense particles make irregular sedimentation. In addition, the large round structures with the same size arise in various parts and the content is so low in density that they are presumably coincident to vacuolized big granules which could be distinguished in their shape and localization from the vacuoles identical with the intermediate dilatation of tubular invagination mentioned above.

In the adult ( 60 days of age) there are sometimes the another large granules, $500 \mathrm{~m} \mu$ in diameter, in the cytoplasm. They resemble lysosomes, as the dense particles are ramdomly concentrated in them (Fig. 15). It has been informed that the cells of the proximal con- 
voluted tubules include frequently pigment granules, absorbed dropletes and microbodies, but the present observation failed to distinguish them exactly. On the other hand, moderately dense granules 0.5-1.0 $\mathrm{m} \mu$ in diameter are observed near the mitochondria; these granules seem to be concerned with the degenerating mitochondria, because they are surrounded by the limiting membrane, and they contain the vestigue of cristae or something as filaments (Fig. 15).

In this observation the origination of big granules was suggested: it was noted that the big granule was adjacent to the vacuole or sack of tubular invagination, as if it were invaginated into the sack (Fig. 16). The content of vacuoles may be transfered into granules by diffusion to increase gradually its density. If the diffusion is possible through the membrane, the dense granules might be resulted from the inflow of urine consitituents via tubular invagination. Lysosome-like substance and hyaline droplet appear to be degenerative sign or at least the inactive. Reliable identification of both structures is not successful. Concerning the significance of big granules, the authors considered it reasonable that some of them might be absorbed granules.

\section{5) Relationship between branchlets from vacuoles and underlying rough endoplasmic reticulums}

Pursuing whether the exits are situated on the surface of vacuoles, the authors have learned that the descending branchlets similar in structure to the tubular invagination are dispatched from vacuoles. However, the branchlets go only in short distance and thereafter disperse in the cytoplasm (Fig. 17). Therefore the vacuoles are surely intermediate sacks along the tubular invaginations, although the fate of branchlets was not determined on a section. Meanwhile, there occur frequently slender endoplasmic reticulums extending themselves long from the vicinity of exits to the infranuclear region (Fig. 19). Their entire passage was unable to be detected without the examination of the serial ultrathin sections. As for the profiles, it was understood that the slender endoplasmic reticulums perpendicularly get to the basement membrane (Fig. 19). It was not sure whether both of them were communicated or not, but the branchlets seem to acquire ribosomes gradually on their smooth membrane, as indicated in Fig. 18 ; the branchlets are possibly of rough surfaced appearance. However, the frequency of 
branchlets is so low that their functional significance should not be overestimated.

\section{6) Basal compartment}

The shape and density of the basal compartments vary in degree with the development of nephrons. They do not develop in the primordial tubule, but the compartments are differentiated even at birth in the late nephron appearing at the innermost area of cortex. The differentiation of basal compartments is generally in equilibrium to the development of microvilli. According to the authors' view, they may be nothing but the longitudinal or oblique sections of the interlocking cytoplasmic plicae, because they are surrounded by the double plasmamembranes of the facing cells. The augmentation in frequency may stand for the complicated fluted cell surface, and in the adult the compartments are most frequently found to invade deeply the superficial portion from the basal part in order to build up an elongated dome. The $\beta$-cytomembrane by $\mathrm{S}$ jöstrand (1956) may be synonymous with the double membranes of the compartments. Meanwhile Suzuki (1958) did not accept the reality of the compartment but formed a conception of basal intussusception according to his developmental investigation: basal intussusception begins with the formation of small vesicular components, and when maturated they are joined to make the invaginated continuous dome-like plate analogous with the $\beta$-cytomembrane surrounding the compartments. The present authors do not agree with S u z k i's hypothesis about the genesis of the $\beta$-cytomembrane.

\section{7) Foot processes on the basal surface of the cells}

The basal surface of the lateral plicae in cells of proximal convoluted tubule is provided with many tiny foot processes, which bulge slightly in the basal space between the cytoplasm and basement membrane (Fig. 19). The double plasmamembranes are invaginated in short distance between foot processes and curved, making sometimes a circuit or a secondary compartment. The compartment of foot processes may depend upon the oblique section of interlocking foot processes. In general, the cells of proximal convoluted tubule are devoid of the real basal infoldings. After the 12th day, the foot processes begin to develop from the peripheral part of cell-body in the late nephrons appearing at the inner area of cortex. The differentiation of foot process is behind that of 
lateral plicae. The basal space and the space between the foot processes are not always closed but sometimes dilated. On a tangential section, the space reveals the fused pool in which many foot processes are interlocking, representing a mosaic pattern (Fig. 20).

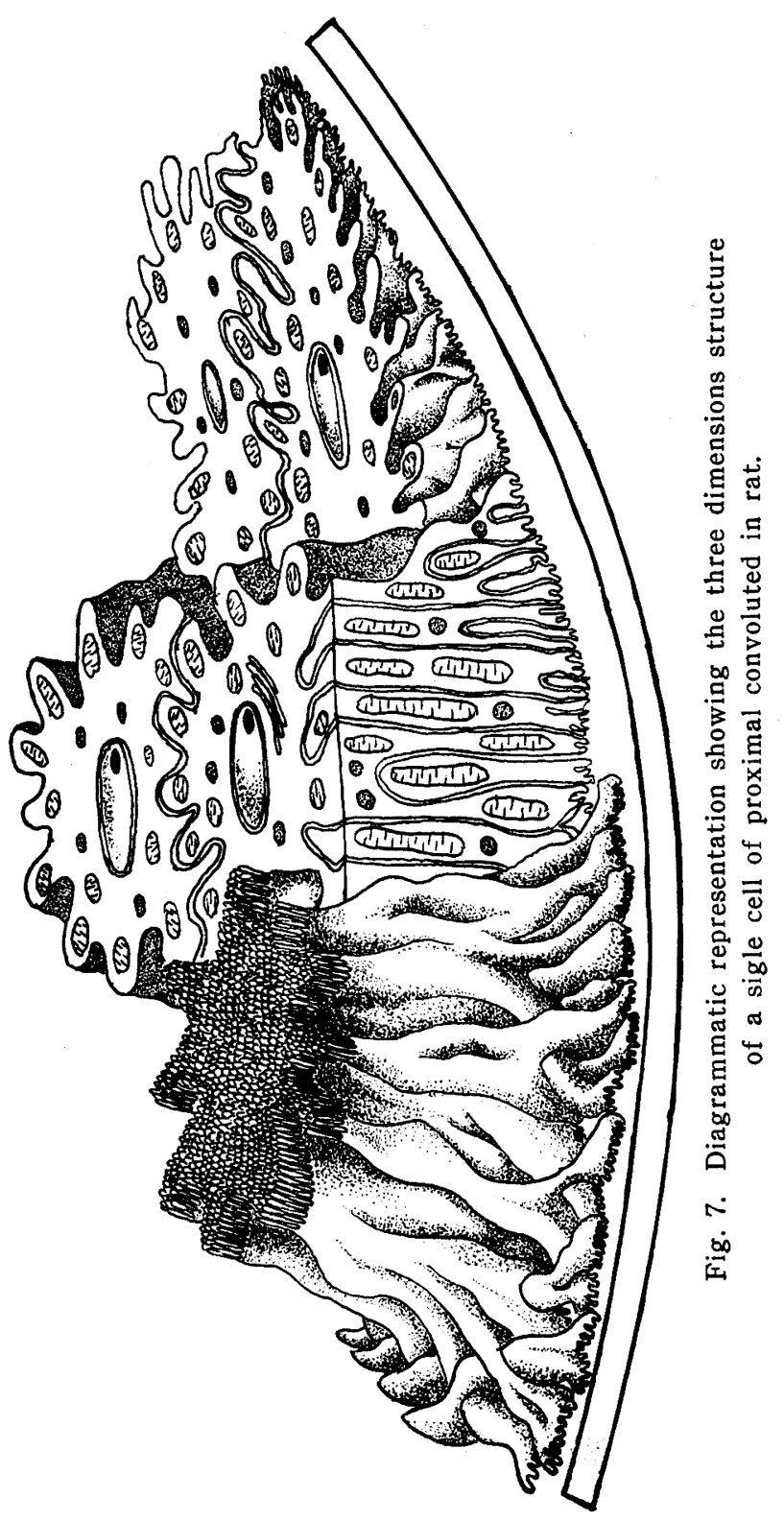




\section{8) The outline of a single cell}

The contour of a cell is simplified during the primordial period, while that in the late nephron comes gradually to be complicated. A cell tangentially, transversally or obliquely sectioned commonly reveals the outline with the exaggerated tortuosity: on a oblique section, the plasmamembrane is constantly in puzzule (Fig. 23); on a transversal section, it bends densely like labyrinthus (Fig. 21). If a cell is cut perpendiculary, the plasmamembrane runs straightly from terminal bar to basement membrane (Fig. 22). These straight plasmamembranes are quite numerous within a single cell and distributed in parallel with the narrow interval, in which rodlike mitochondria are imposed perpendicularly. The oblique sections of flute cell surface manifest a compartment bordered by the plasmamembrane. The numerous occurrence of perpendicular plasmamembrane may be responsible for the profiles of fluted cell-surface owing to the lateral plicae ranging continuously from terminal bar to the basement membrane. When a cell is sectioned tangentially through the plane of terminal bar, the cell-outline represents the stellata by its many plicae (Fig. 24). A diagrammatic representation of our observation was summerized in Fig. 7. Such a labyrinthus of plasmamembrane as in the apical part of cell-body has not been pointed out by $\mathrm{R}$ hodin (1958). Therefore his schema should be modified in this respect as well as in the finding of tiny foot processes. This complicated outline of the cell in proximal convoluted tubule had already been demonstrated by Zimmermann (1911), who disclosed the cell-outline by silver impregnation and iron-hematoxylin stain in the $\operatorname{dog}$ and the cat. His classical contribution is of great value. The lateral plicae of the cell are formed profusely in equivalent with the development of nephron, and in the adult they are most prominent in density and in interlocking.

\section{Discussion}

Two major functions of the proximal convoluted tubule are secretion and reabsorption, and the latter is apparently predominant. function. Physiological evidences have converged to show that a large part of absorbed water is involved in the proximal convoluted tubule. The isosmotic reabsorption called obligatory always occur under the normal condition. Salt is absorbed with the solution; glucose is absorbed by the cells of the proximal convoluted tubules. 
Meanwhile, secretion or excretion of usual urinary constituents is not likely to occur to great extent in the mammals, though creatinin and probably some potassium are excreted in man ( $\mathrm{S} \mathrm{m}$ it h 1951).

According to the authors' view, the ultrastructure of the proximal convoluted tubule concerned with the picture of reabsorption shows the tubular invagination and the implicated vacuoles. Urine consituents and fluid are possibly transfered through the tubular invagination and stored temporalily in vacuoles, and the content is modified during the storage by the enzymatic action and changed into some substances to be eliminated by diffusion through the membrane. Miller (1960) stated that the hemoglobin absorbed by the cells of the proximal convoluted tubule in mouse kidneys enters the tubular invagination and are transported in bulk into vacuole. This is in agree with our view. Miller was convinced that the vacuoles would be thereafter transformed into dense reabsorbed droplets. It is not sure to us whether vacuoles turn directly into big granules, because big granules, according to our observation, may be formed by the diffusion of the content of adjacent vacuoles. $\mathrm{S} \mathrm{ch} \mathrm{midt} \mathrm{(1960)} \mathrm{assumed} \mathrm{a} \mathrm{role} \mathrm{of} \mathrm{Golgi} \mathrm{apparatus} \mathrm{in} \mathrm{concentra-}$ tion of trypanblue granules by his electron microscopic investigation. However, from the results of our observation on the Golgi complex, this hypothesis cannot be accepted, because in most cells under the various postnatal developmental stages the Golgi complex is not developed enough. The branchlets frequently spring up from the vacuoles, descending deeply to the basal part. If they are connected with the slender rough endoplasmic reticulum, the content of vacuoles might be transported efficaciously to the innermost area. But evident proof is not avaiable for this concept. If Golgi lame7lae are related to the reabsorption, they may achieve some participation in the connection of the branchlets to the slender endoplasmic reticulums.

It is worthy of notice that the total space surrounding the whole cell surface is of great dimension, because the lateral plicae are extraordinarily large and numerous. Although the tight junction between cells is extended in the proximal convoluted tubules in the early nephron, it is hard to find out frequently the elongated tight junctions on the tangential sections in the adult nephron. Under the normal condition, as the double membranes of opposite cells are stuffed with some materials at the tight junction, the fluid could not pass away through it. If some agencies affect the tight junction to urge the elimination of fluid, some urinary content 
might flow out through the intercellular space from the lumen to the basement membrane. Therefore, this picture fits in with the efficacious reabsorption of water, though there is a contradictory opinion that the tight junction could not be opened in any cases. Absorbed fluid flows simultaneously into the space between the double membranes surrounding the compartment, which may act as ion pomp to raise the reversal flow against the blood stream with an aid of energy from mitochondria adjacent to the plasmamembranes (R u ska, Moore and Weinstock 1957). It was also learned that the entire surface of a single cell was immersed in the environmental fluid.

Rollhäuser and Vogell (1957) made electron microscopic observations on the proximal convoluted tubule of rats given phenolred and per-abrodil. According to them, the injected materials seem. to be accumulated in vacuoles after passing the basement membrane; these much or less spindle-shaped vacuoles originated from the dilatation of the interspace between the double membranes communicate reversely in cript-like formation connected with the striated border. These investigators, therefore, regarded them as the precursor of secretory materials. In addition, $\mathrm{R} 01 \mathrm{lh} \mathrm{h} u \mathrm{ser}$ (1957) pointed out that phenol-red was excreted out in the proximal convoluted tubule through the entire canalicular unit, while glucose was reabsorbed through the identical route. Therefore, it may stand the purpose of both reabsorption and excretion. Concerning a variety of inclusion bodies in the cells, Montgomery and Breem e n (1958) distinguished them into pigment granule, hyaline droplet, hemosiderin granule, absorption droplet, excretion body and lysosome etc. In their electron microscopy with the materials of dog, rabbit, rat and mouse, they came to a tentative conclusion that these inclusions should be united in lysosomal category. In the present observation, it was controversial whether all kinds of big granules deal with the absorbed granules. At least, there are no. evidences of the secretion to be supported by our electron microscopy.

\section{Summary}

The cells of the proximal convoluted tubules in the newborn, postnatally developing and adult rats were investigated light and electron microscopically.

1) The postnatal development of nephron varies in degree with 
their localization in cortex : the deeper the nephrons are present, the more their development is progressive. At birth, the additional neoformation of nephrons originated from the blastema continues beneath the capsula till the 9th day, and thereafter mitosis occurs successively till the adult's age in the cells of proximal convoluted tubule in order to prolong the length of the nephron.

2) In the central area of the primordial tubule, the double plasmamembranes begin to bend singlly between cells. The dense bendings and the subsequent induction of alienation of membranes result in the initial formation of lumen. The inner and outer membranes forming the dense flexions are left separated, and turn into the microvilli veiling both surfaces of the lumen.

3) Tubular invagination formation is synchronized with the development of microvilli. In the cells of the late nephron in newborn rats, the density and elongation of the invaginations are progressive in degree. The invagination is a flat channel-like tubule bordered with the smooth membrane.

4) The vacuoles appearing beneath the brush border are synonymous with the intermediate dilations or sacks of the tubular invaginations. The vacuoles are irregular and often flat in shape.

5) The branchlets often spring up from the vacuoles, but the fate of branchlets was not determined. It is tentative that they are connected with the slender rough endoplasmic reticulums ranging from the vicinity of vacuoles to the basement membrane.

6) Big granules are present in the various area of cell-body in the late nephron. Some of them invaginate into vacuoles. There is an evidence that they might be resulted from the diffusion of the content of vacuoles through the membrane.

7) The cells are provided with the numerous lateral plicae. The basal compartments are identical with the various profiles of the fluted cell surface. The lateral plicae range successively from the terminal bar to the basement membrane.

8) The cells of the proximal convoluted tubule in the primordial nephron are monotonous in contour, but with a progress in develepment of nephron the shape of the cells become complicated; in the late nephron the cells look stellata with the labyrinthus of plasmamembrane on a transversal section. The entire surface of the cell is extraordinarily extended because of the outstanding complication of lateral plicae.

9) In the fully differentiated nephrons, numerous tiny cytoplasmic processes bulge in the basal space between the cytoplasm 
and the basement membrane. On a tangential section, they show mosaic pattern in the basal space. The functional significance of the above ultrastructures has been discussed.

\section{References}

1. Arataki, M.: On the postnatal growth of the kidney with special reference to the number and size of the glomeruli (albino rat). Amer. J. Anat. 36: 399436, 1926.

2. B a x te r, J.S. and J.M. Y of f e y : The post-natal development of renal tubules in the rat. J. Anat. $82: 189-197,1948$.

3. C 1 a r k, Jr. S. L.: Cellular differentiation in the kidneys of newborn mice studied with the electron microscope. J. Biophys. Biochem. Cytol. 3 : 349-362, 1957.

4. E 1 i a s, H.: The nephron by light and electron microscopy. Anat. Rec. $128: 544$, 1957., Amer. Soc. of Zoology.

5. Davies, J.: Cytological evidence of protein absorption in fetal and adult mammalian kidney. Amer. J. Anat. 94: 45-62, 1954.

6. Kittels on, J.A.: The postnatal growth of the kidney of the albino rat, with observation of an adult human kidney. Anat. Rec. 13 : 385-408, 1917.

7. L e e son, T.S.: An electron microscopic study of the mesonephros and metanephros of the rabbit. Amer. J. Anat. 195: 165-196, 1959.

8. - Electron microscopy of the developing kidney: An investigation into the fine structure of the mesonephros and metanephrons of the rabbit. J. Anat. 94 : 100-106, 1960.

9. Mille r, F.: Hemoglobin absorption by the cells of the proximal convoluted tubules in mouse kidney. J. Biophys. Biochem. Cytol. $8: 689-718,1960$.

10. Millonig, G.: Advantages of a phosphate buffer for $\mathrm{Os}_{4}$ solutions in fixation. J. Appl. Physics 32: 1637, 1961.

11. Mont g o mery, J.D. and V.L. van Breemen: Observation on kidney tubule cell inclusion bodies. Anat. Rec. $130: 457,1958$. A. A. A.

12. Pease, D.C.: Electron microscopy of the tubular cells of the kidney cortex. Anat. Rec. $121: 723-743,1955$.

13. Policard, A., A. Collet et L. Giltaire-Raly te: Étude au microscope électronique de la "bordure en brosse" du tube mammifères. C. R. Acad. Sci. 239 : 936-938, 1954.

14. Rey nalds, E.S.: The use of lead citrate at high $\mathrm{pH}$ as an electron, opaque stain in electron microscopy. J. Cell. Biol. $17: 208-212,1963$.

15. Roh di, $\mathrm{J}$.: Correlation of ultrastructural organisation and function in normal and experimentally changed proximal convoluted tubule cells of the mouse kidney. Thesis, Karolinaska Inst., Stockholm. 1-76, 1954.

16. - Anatomy of kidney tubules. Internat. Rev. Cytol. $7: 485-534,1958$.

17. - Electron microscopy of the kidney. Amer. J. Med. $24: 661-675,1958 \mathrm{~b}$.

18. Rollhäuser, H.: Polarisationsoptische und histochemische Untersuchungen über die Feinstructur des Nephrons und ihre Beziehungen zur Nierenfunktion. $Z$. Zellforsch. 44 : 57-81, 1956.

19. Rollh äuser, H. und W. Voge11: Elektronenmikroskopische Beobachtungen über die aktiven Ausscheidungen an der Niere. Z. Zellforsch. $47: 53-76,1957$.

20. Ruska, H., D. H. Moore and J. Weinstock: The base of the proximal convoluted tubule cells of rat kidney. J. Biophys. Biochem. Cytol. 3 : 249-254, 1957. 
21. Schmidt, W.: Elektronenmikroskopische Untersuchungen über die Speicherung von Trypanblau in den Zellen des Hauptstücks der Niere. Z. Zellforsch. 52 : $598-603,1960$.

22. Sjöstrand, F.S. and J. Rhodin: The ultrastructure of the proximal convoluted tubules of the mouse kidney as revealed by high resolution electron microscopy. Exp. Cell. Res. 4: 426-456, 1953.

23. Sjöstrand, F.S.: Ultrastructure of cells as revealed by the electron microscope. Internat. Rev. Cytol. $5:$ 455-533, 1956.

24. S mith, H.W.: The kidney. Structure and function in heath and disease. Oxford Univ. Press, New York. 1951.

25. Suzuki, Y.: An electron microscopy of the renal differentiation. 1. Proximal tubule cells. J. Electronmicroscopy $6: 52-65,1958$.

26. We is s, J.M.: Intracellular changes due to neutral red as revealed in the pancreas and kidney of the mouse by the electron microscope. J. Exp. Med. 101 : 213-224, 1955.

27. Z i m merm a n n. K. : Zur Morphologie der Epithelzellen der Säugetierniere. Arch. mikros. Anat. 78 : 199-231, 1911. 


\section{Plate I}

\section{Explanation of Figures}

Fig. 8. The most initial phase of microvilli formation in the primordial tubule, rat, the first day. The double plasmamembranes bend here and there. The invaginated cytoplasmic processes (cp) are of high electron density. ti, tubular invagination; er, rough endoplasmic reticulum; tj, tight junction. $\times 18,000$

Fig. 9. The most initial phase of luminal formation in the primordial tubule, rat, the first day. The wide space is interposed between the plasmamembranes, and tubular invaginations (ti) are formed numerously. cl, cilla. $\times 15,000$ 
Plate I
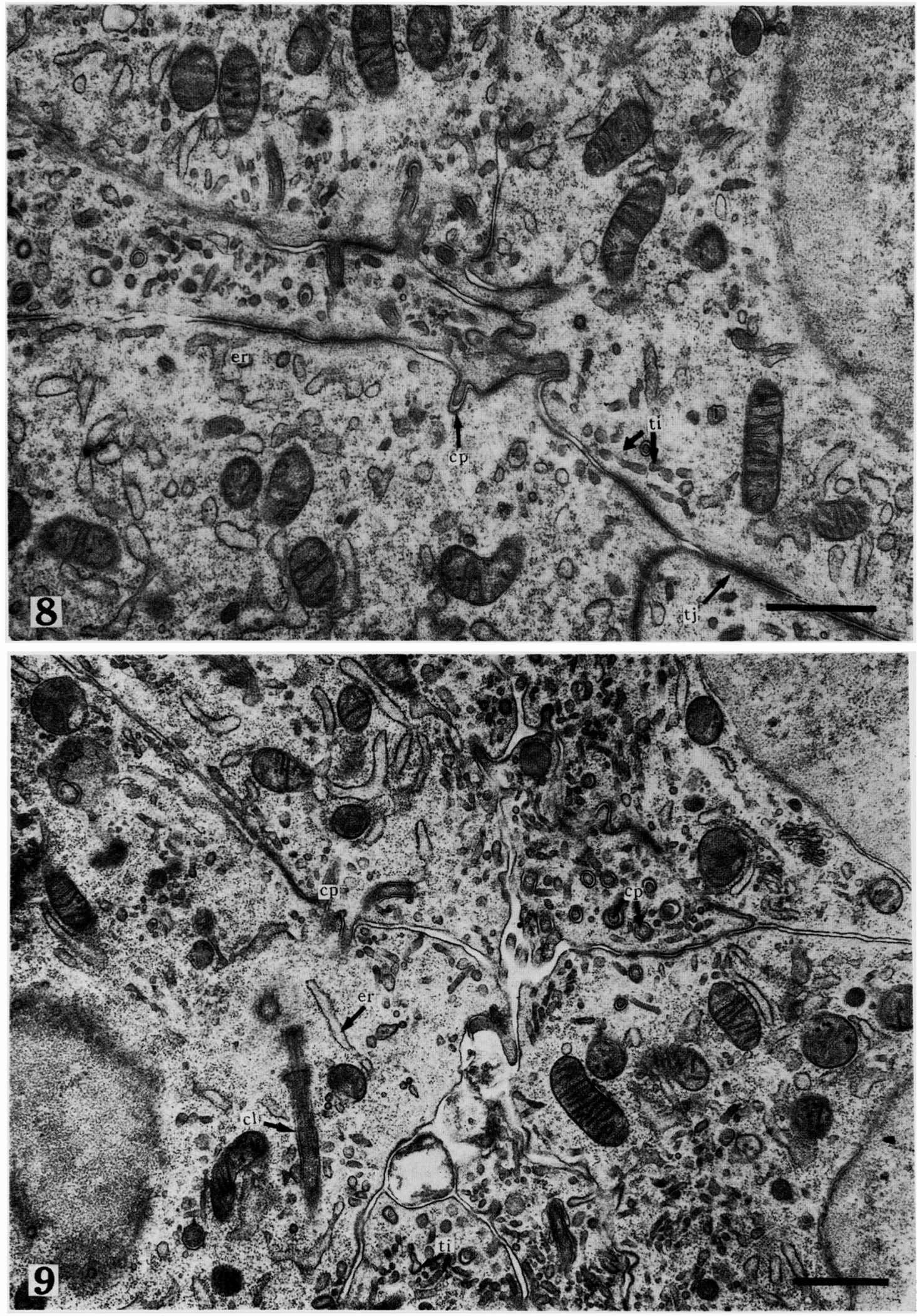

F. Yoshimura and Mi. Nakamura 


\section{Plate II}

\section{Explanation of Figures}

Fig. 10. The luminal formation in the primordial tubule, rat, the third day. The space among the plasmamembranes is expanded; the luminal surface is not always equipped with the microvilli. Many tubular invaginations branch off already. $\times 10,000$

Fig. 11. The luminal formation in the primordial tubule, rat, the 4 th day. Microvilli become quite numerous. The tubular invaginations end into the small vacuoles $(\mathrm{sv})$, associated with the large vacuoles (1v). $\times 15,000$ 
Plate II
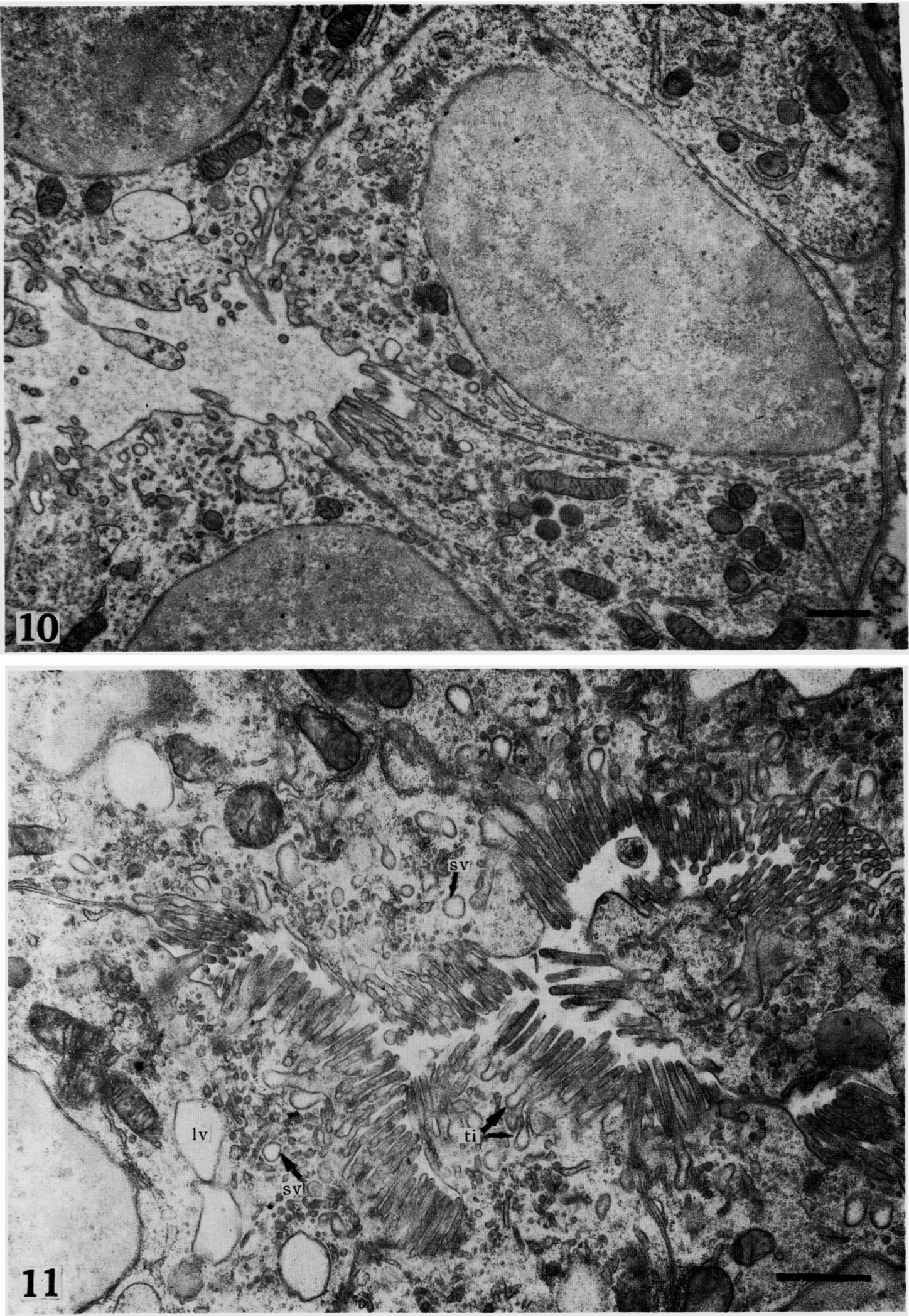

F. Yoshimura and M. Nakamura 


\section{Plate III}

\section{Explanation of Figures}

Fig. 12. The cells without the microvilli in the primordial tubule, rat, the 4 th day. The cytoplasm facing the closed lumen is devoid of microvilli, while the opposite cell is distinctively provided with them. The density in distribution of microvilli is compatible with that of tubular invaginations in the apical part of cell-body. bg, big granules with high density; Gc, Golgi complex. $\times 14,000$

Fig. 13. Vacuoles in the cells of proximal convoluted tubule, rat, the 9th day. Numerous vacuoles of irregular shape are distributed in a row beneath the brush border. Tubular invaginations are profuse. $\times 12,000$ 
Plate III
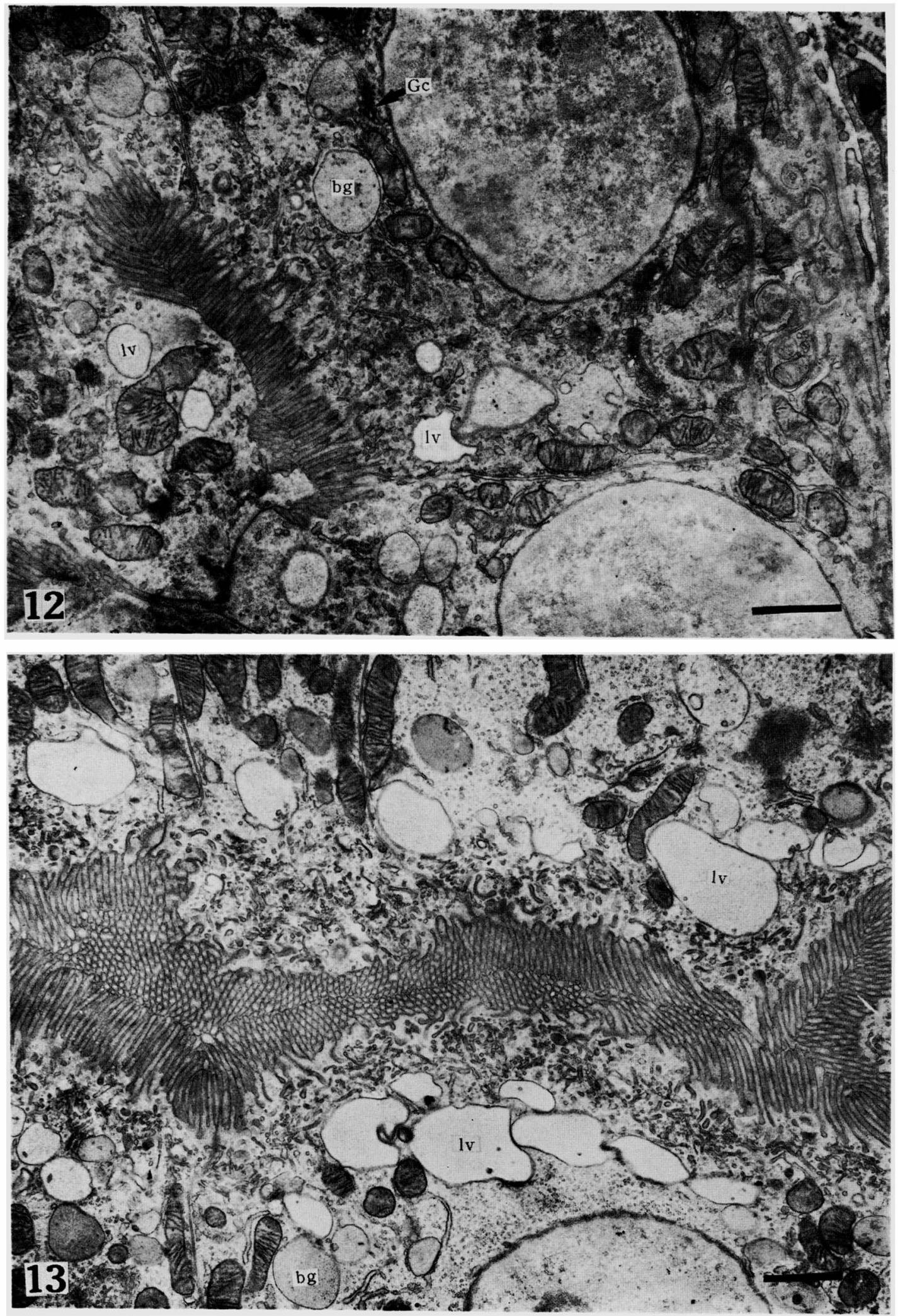

F. Yoshimura and M. Nakamura 


\section{Plate IV}

\section{Explanation of Figures}

Fig. 14. Abundant big granules which are present temporalily after the birth in the cells of proximal convoluted tubule, rat, the second day. Extraordinarily numerous big granules arise at the whole area of cell-body. They, surrounded by the limiting membrane, are of moderate density. $\mathrm{fg}$, fat granule. $\times 10,000$

Fig. 15. The cells of the proximal convoluted tubules in the adult rat, 60th day. In the adult, the cells usually contain big granules, with which are mingled the lysosomal granules (1s). $\mathrm{dm}$, the granules which seem to be concerned with the degenerating mitochondria; bm, basement membrane; fp, foot process. $\times 10,000$ 

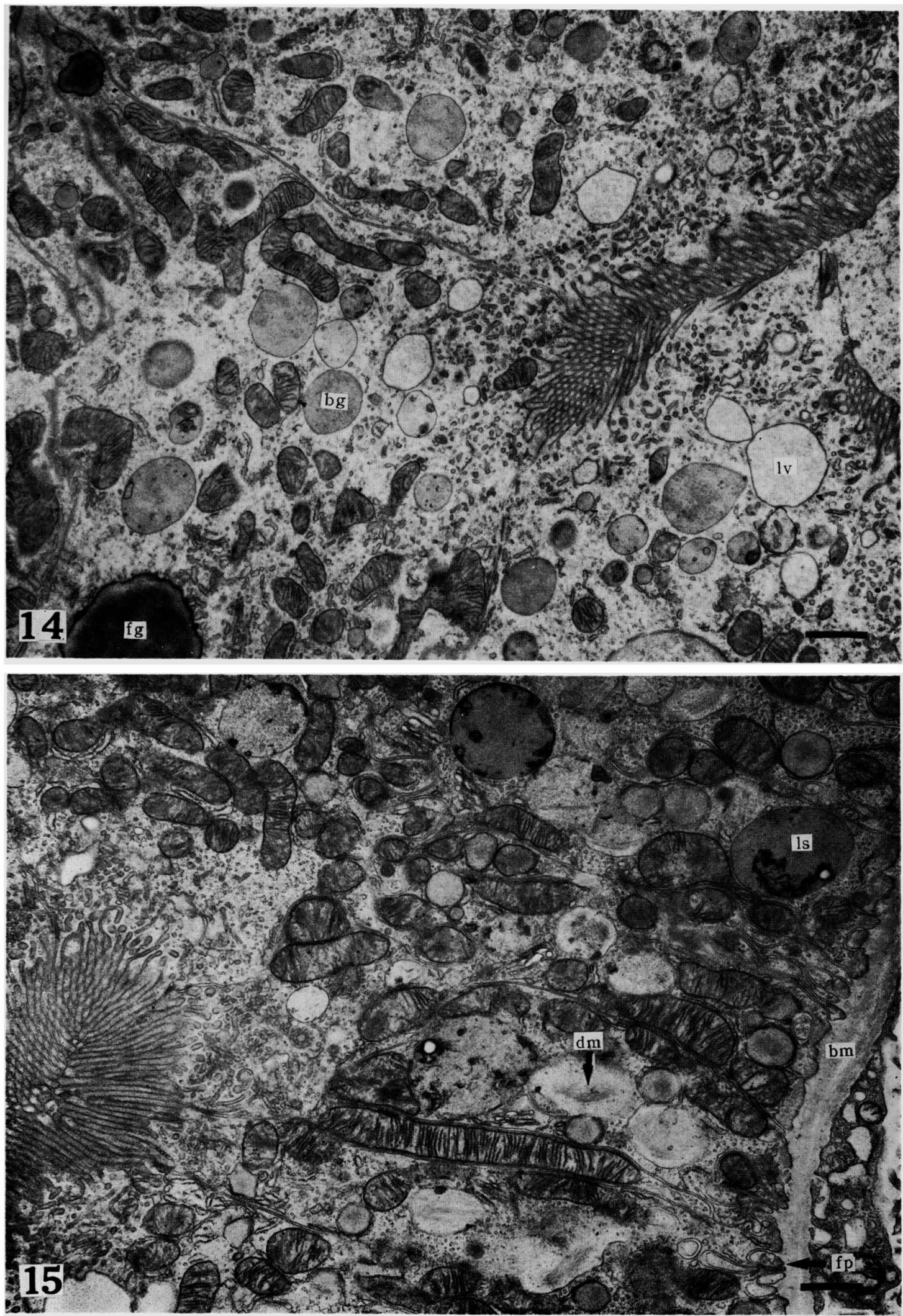

F. Yoshimura and M. Nakamura 


\section{Plate V}

\section{Explanation of Figures}

Fig. 16. The big granules invaginating into the vacuoles in a cell of proximal convoluted tubule, rat, the 15 th day. $\times 17,000$

Fig. 17. Vacuoles beneath the brush border and the branchlets dispathched from them in a cell of the proximal convoluted tubule, rat, the 18 th day. The elongated branchlets (br) of high electron density spring off from the vacuoles and dispersed in the cytoplasm; the vacuoles may be an intermediate sack along the tubular invagination. $\times 30,000$

Fig. 18. The branchlets dispatching from the vacuoles in a cell of proximal convoluted tubule, rat, the 18 th day. This branchlet (br) becomes gradually to be likely equipped with rough surfaced limiting membrane (arrow). $\times 23,000$ 
Plate V
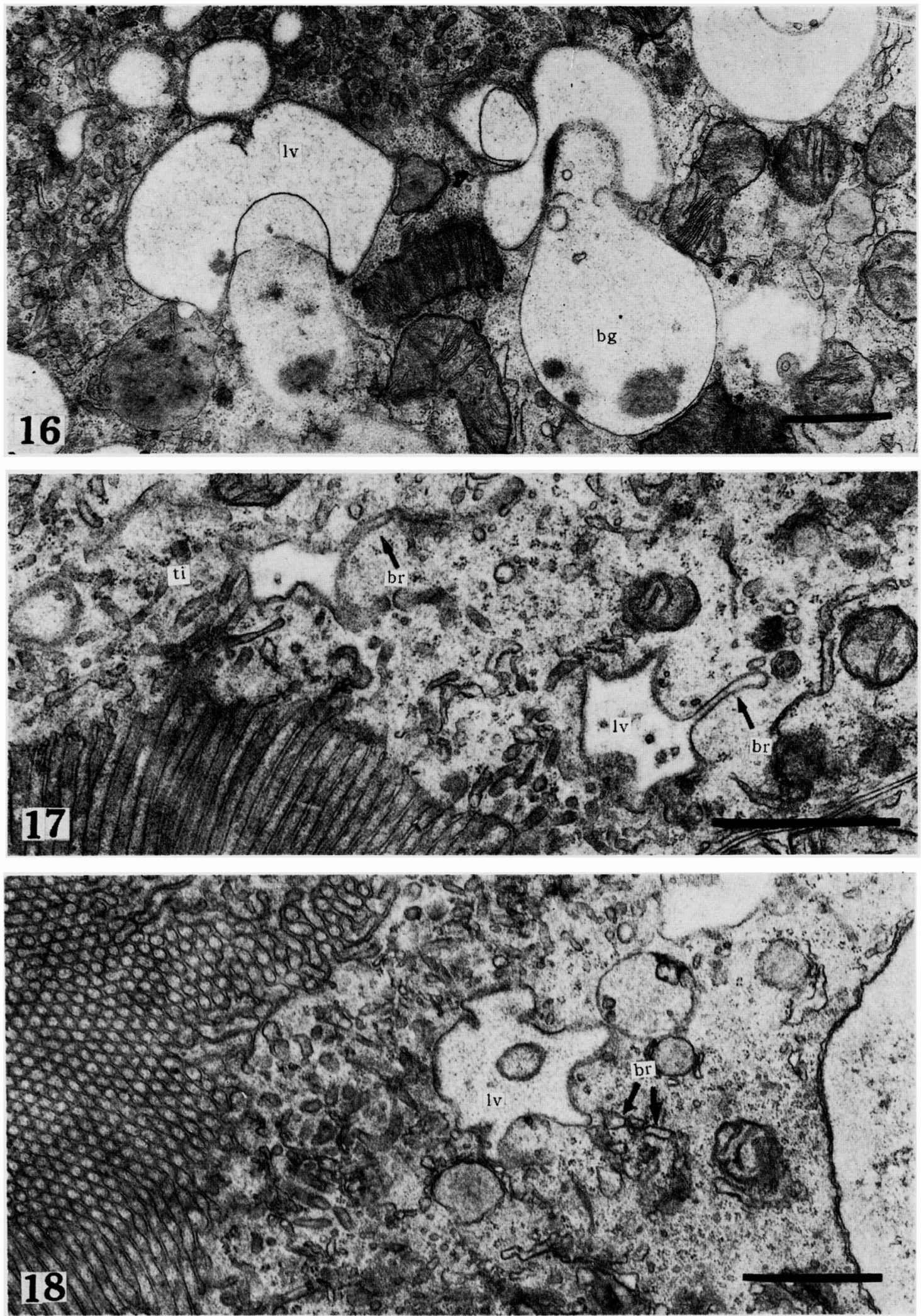

F. Yoshimura and M. Nakamura 


\section{Plate VI}

\section{Explanation of Figures}

Fig. 19. A perpendicular section along the cell-axis of a cell of proximal convoluted tubule, rat, the 50th day. The compartments (cp) surrounded by the double plasmamembranes are seen frequently in the cell, and on the basal surface there exist numerous foot processes which are interlocking each other. The slender elongated canalicular endoplasmic reticulums (cer) run occasionally downwards to the basement membrane. $\times 16,000$

Fig. 20. A tangential section through the basal part of a cell of proximal convoluted tubule, rat, the 40 th day. The tiny foot processes interlock in the dilated space. $\times 11,000$

Fig. 21. A transversal section through the apical part of a cell of proximal convoluted tubule in the late nephron, rat, the first day. The plasmamembranes between cells are profoundly crooked, representing a labyrinthus. plm, crooking plasmamembrane. $\times 18,000$ 
Plate VI
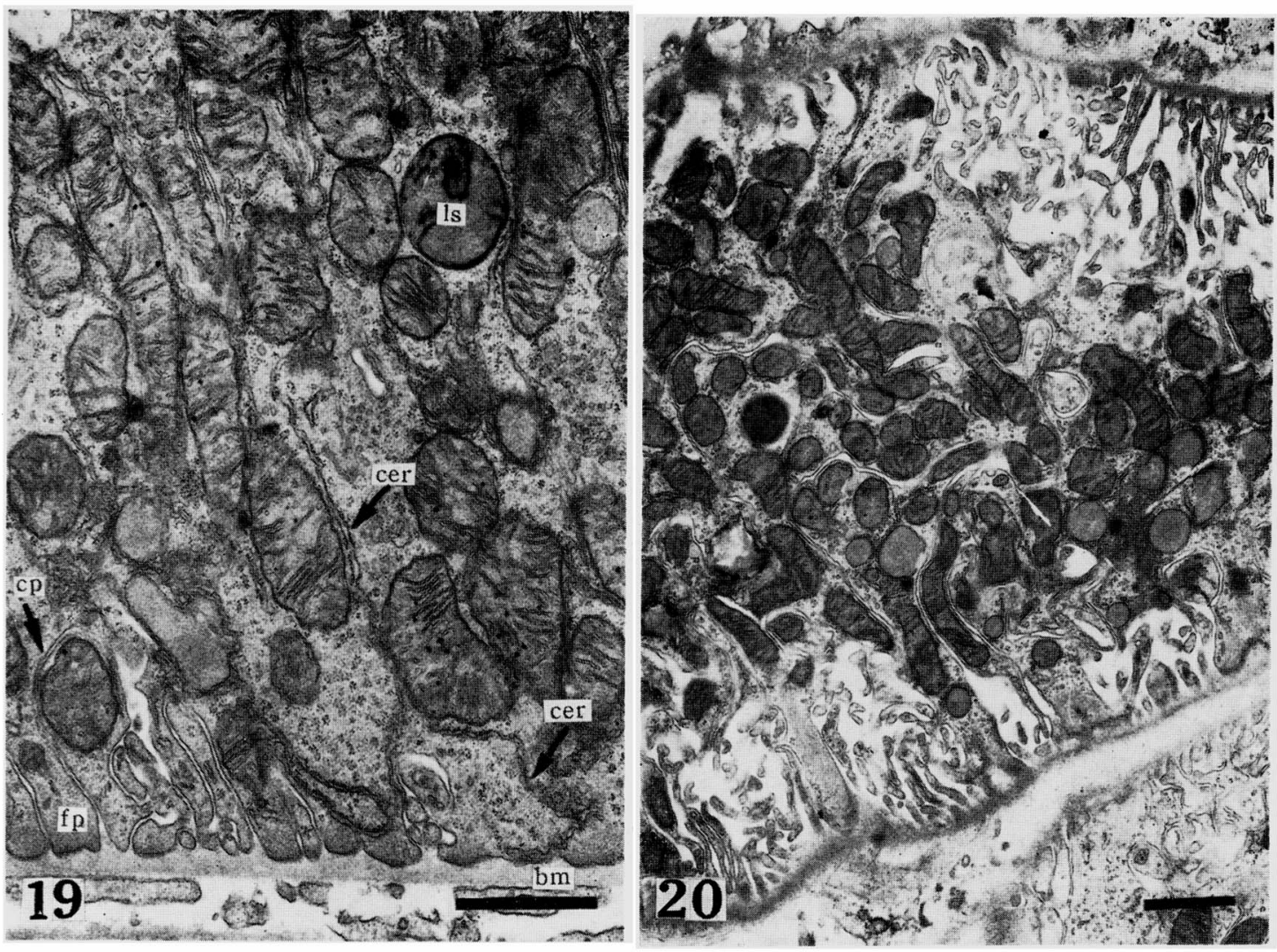

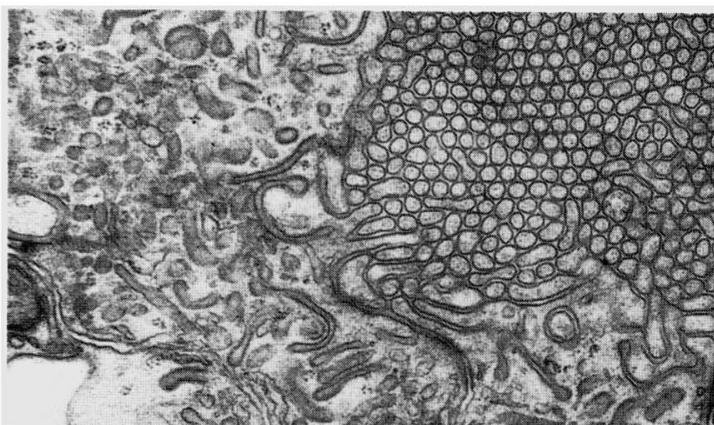

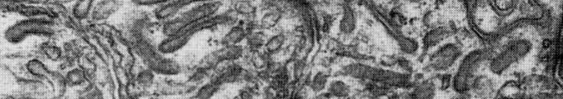

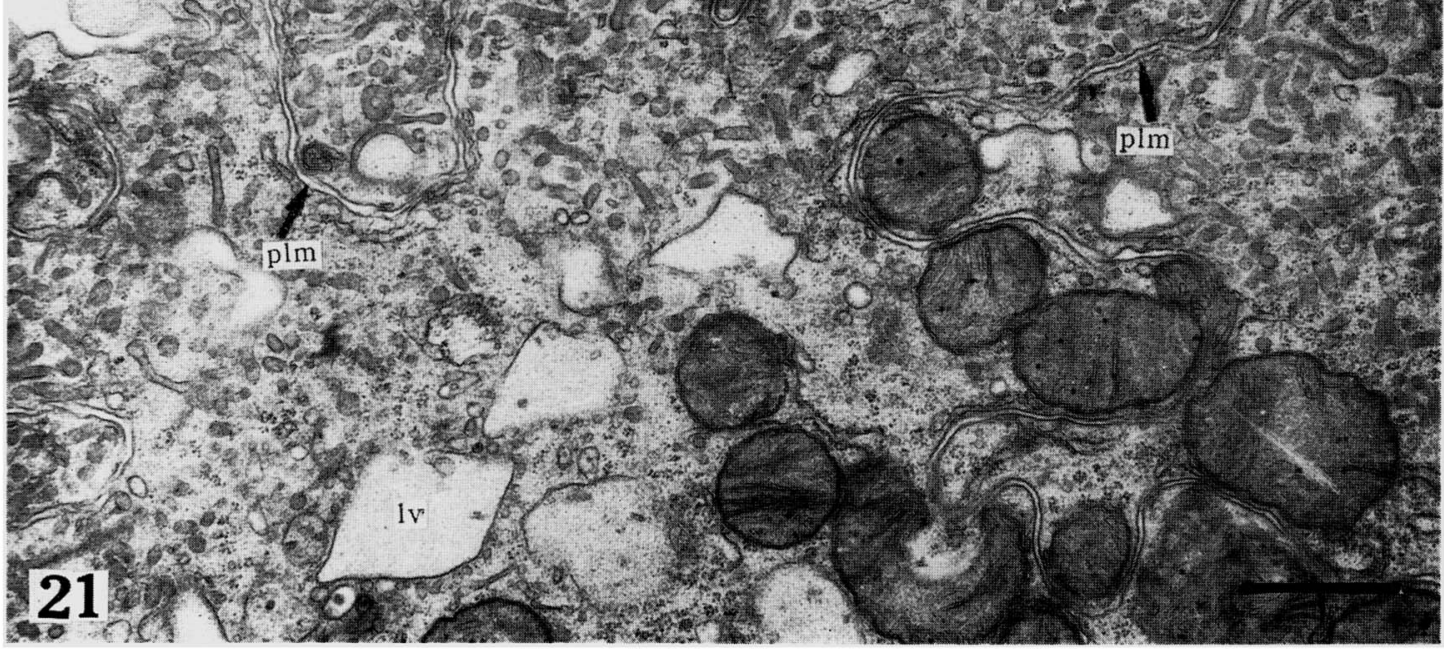

F. Yoshimura and M. Nakamura 


\section{Plate VII}

\section{Explanation of Figures}

Fig. 22. A perpendicular section of a cell of proximal convoluted tubule, rat, the 15 th day. The double plasmamembranes (plm) run straightly in parallel, and this picture manifests a profile of fluted cell surface. $\times 17,000$

Fig. 23. An oblique section of the cells of proximal convoluted tubule, rat, the 40 th day. The plasmamembranes between cells are extremely complicated in puzzule (arrow). $\times 11,000$ 

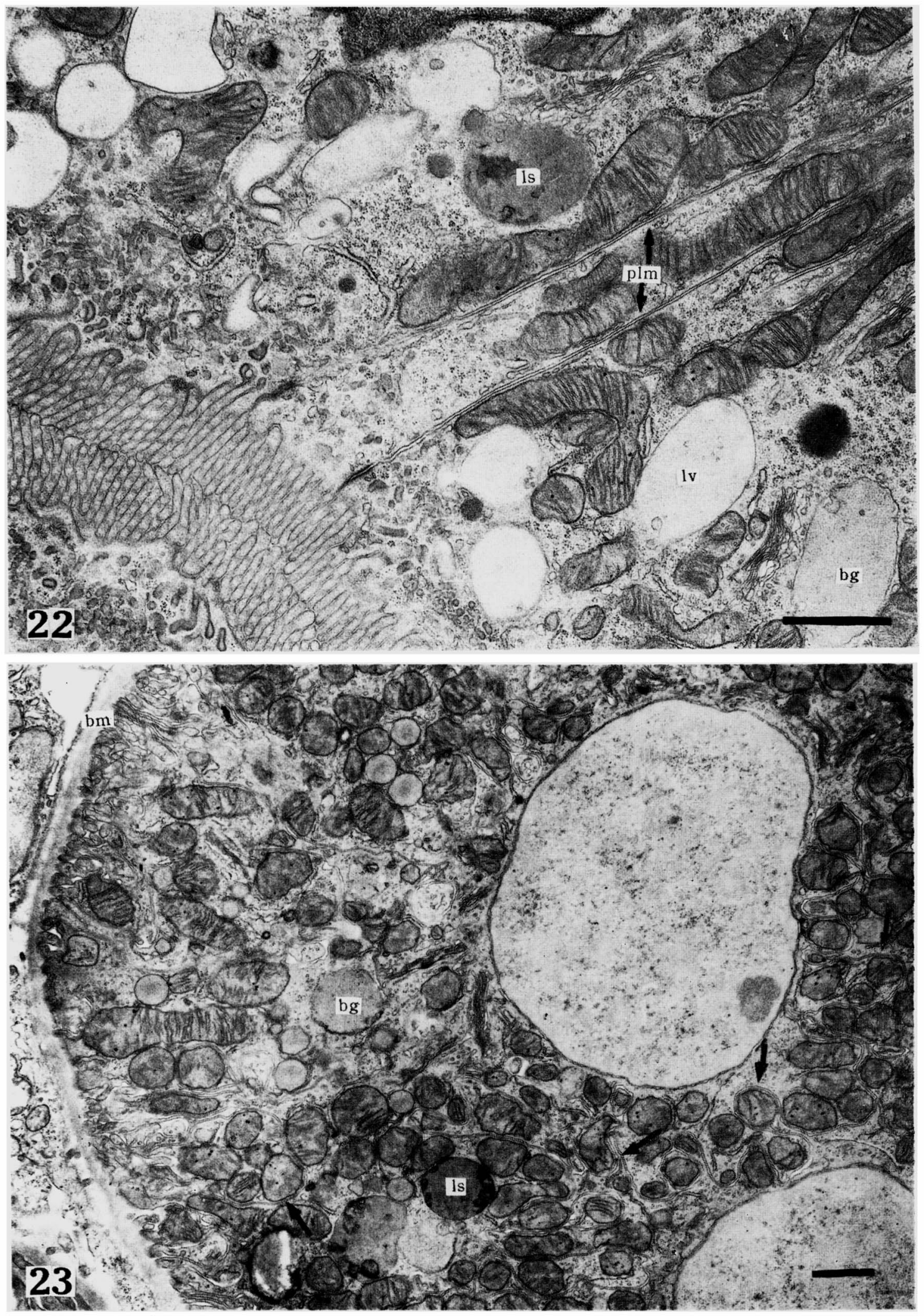

F. Yoshimura and M. Nakamura 